\title{
PERSPECTIVAS DE USO DO SISTEMA DE CREDENCIAMENTO PARA AMPLIAR A EFICIÊNCIA DE PROCESSOS LICITATÓRIOS
}

\author{
PROSPECTS OF USING THE ACCREDITATION SYSTEM TO INCREASE EFFICIENCY \\ IN PROCUREMENT PROCESSES
}

\author{
Waldemiro Francisco Sorte Junior \\ Ministério da Economia, DF, Brasil \\ E-mail:waldrusso@gmail.com
}

Recebido em: 12.06.2020 - Aceito em: 13.08.2020

DOI: http://dx.doi.org/10.5902/2526629247213

RESUMO: Com base em um estudo de caso envolvendo um sistema de credenciamento de companhias aéreas implementado pelo Governo Federal para a aquisição de passagens para viagens a trabalho de servidores públicos, este artigo defende a possibilidade de utilização do credenciamento para imprimir maior celeridade e eficiência em contratações públicas. No caso examinado neste estudo, foram identificadas as seguintes circunstâncias responsáveis pelo sucesso do modelo: (i) existência de um número limitado e identificável de fornecedores; (ii) possibilidade de que todos esses fornecedores sejam credenciados, desde que atendam aos requisitos; (iii) mecanismos que minimizem a formação de conluios entre credenciados; e (iv) realização de minicompetições ou possibilidade de comparação online de preços atualizados de mercado no momento da seleção do fornecedor para a efetiva contratação. O presente artigo argumenta, ainda, que a definição a priori de preços a serem praticados pela Administração não constitui requisito para todos os casos de credenciamento.

Palavras-chave: Administração Pública; Licitação; Credenciamento.

ABSTRACT: Based on a case study involving an initiative implemented by the Brazilian Federal Government for the accreditation of airlines to procure flight tickets for civil servants on business trips, this article argues that, under certain circumstances, the adoption of an accreditation system can increase the efficiency and speed of public procurement. In the case examined for this study, the following elements were responsible for the success of the model: (i) existence of a limited and identifiable number of suppliers; (ii) equal opportunity for all suppliers to be accredited, as long as they meet the requirements; (iii) mechanisms that can minimize potential collusion between accredited firms; and (iv) the use of mini-com- 
petition or a system to assess the up-to-date market price of the good or service to select a supplier among the accredited firms. This paper also argues that the definition of prices to be paid by the contracting authority beforehand is not a requirement for all the possible uses of the accreditation system.

Keywords: Public Administration; Procurement; Accreditation System.

\section{INTRODUÇÃO}

O credenciamento pode ser definido como o "sistema por meio do qual a Administração Pública convoca todos os interessados em prestar serviços ou fornecer bens, para que, preenchendo os requisitos necessários, credenciem-se junto ao órgão ou entidade para executar o objeto quando convocados" (Requi, 2015). Constitui hipótese de inexigibilidade de licitação, na qual todos os fornecedores têm potencialmente oportunidades equivalentes de serem selecionados em situações em que houver número ilimitado de contratações possíveis, ou "quando a escolha do particular a ser contratado não incumbir à própria Administração" (Justen Filho, 2004, p. 40). Entende-se que o instituto de credenciamento ainda é pouco explorado na literatura acadêmica atual, sobretudo no que tange à possibilidade de novas aplicações, e pretende-se preencher essa lacuna com o presente trabalho. Ao tratar de formas inovadoras de implementação desse instituto, o tema abordado se enquadra na área de políticas públicas, à medida que procura identificar instrumentos que possam aumentar a eficiência e simplificar o processo público de compras no Brasil.

Garantir que os interessados tenham as mesmas condições de se registrarem e de serem selecionados, no âmbito de uma contratação por credenciamento, é crucial, de forma a assegurar a observância do princípio da igualdade, presente no art. $3^{\circ}$ da Lei $n^{\circ} 8.666$, de 21 de junho de 1993 (Brasil, 1993). Medauar (2018, p. 178) conceitua tal princípio como a "isonomia de tratamento para todos os licitantes ou para aqueles que pretendam participar da licitação, vedada qualquer discriminação". Na verdade, além de garantir a igualdade de oportunidades para todos os possíveis licitantes, a promoção da isonomia também se destina a ampliar as chances de que um número maior de interessados participem do procedimento licitatório, para, assim, fomentar a competição, obter uma proposta economicamente vantajosa para a Administração e, consequentemente, otimizar a alocação de recursos públicos escassos. Dessa forma, a isonomia também é relevante para permitir uma competição livre e imparcial. Tal competição constitui fator preponderante na busca da maximização dos resultados em processos licitatórios: 
Existem pelo menos três meios pelos quais a competição pode ser benéfica para o mercado de contratos públicos. Primeiro, com o livre acesso e a ausência de conluio entre compradores e fornecedores, os preços se aproximarão de custos marginais. Segundo, os fornecedores terão incentivos para reduzir seus custos, tais como os de produção, ao longo do tempo. Terceiro, a competição funciona como um importante motor da inovação (Anderson, Kovacic \& Müller, 2012, p. 10, "tradução nossa").

O instituto do credenciamento tende a se mostrar uma alternativa viável por ter o potencial de ser um procedimento mais célere para determinados tipos de contratações públicas. Por outro lado, ao ser enquadrado como hipótese de inexigibilidade de licitação por ausência de competição entre os possíveis licitantes, o credenciamento, da forma em que é usualmente utilizado, elimina a etapa de competição entre os interessados, o que retira a pressão por menores preços. Particularmente, a necessidade de definição a priori pela Administração do valor a ser remunerado pelos serviços a serem contratados mostra-se como um empeciIho à competição por menores preços.

O presente trabalho foi impulsionado pela constatação da necessidade de se explorar modelos alternativos de uso do credenciamento, para que se busquem resultados economicamente mais atrativos para a Administração Pública, sem comprometer o enquadramento do instituto em hipóteses legalmente admitidas de licitações. Propõe-se, então, a utilização do credenciamento como uma forma de imprimir maior agilidade e eficiência a processos públicos de contratação em determinadas circunstâncias. Argumenta-se que o uso desse instituto em certos segmentos de mercado pode resultar em processos mais simples, flexíveis e com menor custo administrativo.

Com esse propósito, examina-se o modelo de credenciamento de companhias aéreas para a aquisição de passagens para viagens a trabalho de servidores públicos da Administração Pública Federal, desenvolvido pela Central de Compras do Ministério da Economia (doravante denominada Central de Compras). Tal sistema não possui aplicabilidade genérica, mas limitada a segmentos de mercado com determinadas condições. Entretanto, merece ser abordado por apresentar uma série de inovações capazes de imprimir maior eficiência ao instituto do credenciamento.

Este artigo encontra-se dividido em cinco seções, incluindo esta introdução. A seção a seguir expõe a metodologia utilizada no estudo. A seção três se dedica a definir o sistema do credenciamento no ordenamento jurídico pátrio, descrevendo suas principais características e requisitos para utilização. A quarta seção apresenta o estudo de caso, que aponta para a possibilidade de um uso mais inovador do referido instituto. A última seção conclui o trabalho. 


\section{METODOLOGIA}

O presente estudo possui como objetivo a discussão de formas alternativas de uso do credenciamento a fim de imprimir maior agilidade e eficiência a processos licitatórios em determinadas situações. Em especial, o artigo defende que a necessidade de definição a priori de preços a serem praticados pela Administração não constitui requisito para todos os casos de utilização desse instituto.

Para a definição das principais características do credenciamento, foi realizada uma pesquisa em fontes secundárias, incluindo não somente a doutrina como também decisões do Tribunal de Contas da União (TCU). Destaca-se que a revisão bibliográfica constitui o instrumento adequado para coletar discussões anteriores sobre determinado tema, para que se possa abordá-lo sob um novo enfoque (Marconi \& Lakatos, 2003, p. 183).

No intuito de explorar a questão central do presente trabalho, utilizou-se como método o estudo de caso (Marconi \& Lakatos, 2003, p. 222). Conforme assinala Yin (2003, p. 13), aplica-se tal método quando se pretende examinar empiricamente um fenômeno que possui substancial pertinência ao objeto de estudo. Assim, entende-se que esse método seja adequado ao presente trabalho, uma vez que permite analisar um caso concreto no qual se fez uso, de forma flexível, do instituto do credenciamento, sem a estipulação a priori do quantum remuneratório a ser pago pela Administração Pública.

Todavia, na medida em que examina um evento por meio de uma abordagem predominantemente qualitativa, o método do estudo de caso se dedica à exploração de uma realidade particular, razão pela qual possui potencial limitado de generalização (Gillham, 2000, pp. 6-9). É certo que o estudo de caso realiza uma análise detalhada de uma unidade singular com a finalidade de promover uma compreensão mais aprofundada de uma coletividade maior de unidades similares (Gerring, 2007, p. 37; Mills, Eurepos \& Wiebe, 2010, p. 23). Não obstante, ainda que as conclusões de um estudo de caso possam ser replicáveis a eventos similares, recomenda-se cautela em generalizações de cunho universal. Por essa razão, apesar de que a análise do modelo de credenciamento descrito no estudo de caso proporcione o alcance do objetivo deste artigo, tal modelo não é diretamente aplicável a quaisquer processos públicos de aquisição, mas somente a situações que guardem elevada similitude às condições do projeto analisado.

O estudo de caso discutido na seção quatro deste artigo foi realizado entre janeiro e julho de 2019 na Central de Compras, unidade da Secretaria de Gestão do Ministério da Economia dedicada à realização de contratações conjuntas de 
bens e serviços de uso comum para órgãos e entidades da Administração Pública Federal. Para a realização do estudo, inicialmente foram conduzidas entrevistas semiestruturadas com coordenadores da Central de Compras, com o objetivo de identificar potenciais aplicações do instituto de credenciamento capazes de imprimir maior eficiência ao processo de compra de determinados serviços. A partir da identificação do credenciamento de companhias aéreas para a aquisição de passagens destinadas a viagens a trabalho de servidores públicos da Administração Pública Federal como modelo pertinente ao objeto deste estudo, foram realizadas entrevistas semiestruturadas adicionais com coordenadores e servidores que trabalharam especificamente no projeto. Também constituíram objeto de análise notas técnicas, pareceres, relatórios e outros documentos referentes a tal projeto.

\section{O SISTEMA DE CREDENCIAMENTO NO BRASIL: CARACTERÍSTICAS E REQUISITOS PARA SUA UTILIZAÇÃO}

O credenciamento não possui, até o presente momento, previsão na legislação federal e não é mencionado dentre os dispositivos da Lei n 8.666/1993. É reconhecido, entretanto, em diversas leis estaduais e aceito pela doutrina e jurisprudência como hipótese de inexigibilidade de licitação. O fundamento para tal instituto está na possibilidade de credenciamento, perante a Administração Pública, de todos os interessados que preencham os requisitos mínimos para a prestação de determinado objeto, em igualdade de condições. Isso porque, havendo um número ilimitado de contratações possíveis e facultando-se o credenciamento de todos os interessados em condições similares, preserva-se o princípio da isonomia e dispensa-se a instauração de uma competição licitatória visando à busca de uma proposta mais vantajosa para a Administração Pública, dada a igualdade das condições de oferta do objeto pelos credenciados. Por essa razão, muitos esforços de conceituação do instituto consideram como requisito para sua utilização a fixação, a priori, do valor a ser pago pela Administração no momento de uma contratação futura. Além disso, como forma de garantir a isonomia, impõe-se a definição de um critério claro e objetivo para a seleção do fornecedor na ocasião da formalização de um contrato, como rodízio ou sorteio, de forma que a escolha do particular a ser contratado não recaia sobre a Administração.

O TCU também entende o instituto do credenciamento "como espécie de inexigibilidade de licitação", conceituado como "ato administrativo de chamamento público de prestadores de serviços que satisfaçam determinados requisitos, constituindo etapa prévia à contratação, devendo-se oferecer a todos igual oportunida- 
de de se credenciar", conforme Acórdão n 1150/2013 TCU-Plenário (TCU, 2013). Assim, exige-se, para a utilização do credenciamento, a existência de um número satisfatório de fornecedores capazes de prestar determinado objeto nas condições exigidas pela Administração e a possibilidade de definição do preço de forma objetiva, com base nas práticas de mercado. De forma análoga, Guimarães (2016) identifica como pressupostos básicos do credenciamento: a existência de uma demanda pública abundante e uniforme de um bem ou serviço; a presença de um mercado privado estruturado e capaz de satisfazer tal demanda; e a definição de uma metodologia de preço objetiva e consistente com as práticas de mercado.

Dessa forma, a utilização do credenciamento no âmbito Federal fundamenta-se no art. 25 da Lei $n^{\circ} 8.666 / 1993$, por constituir caso de inexigibilidade, conforme entendimento jurisprudencial e doutrinário (Ribeiro, 2011; Reis, 2017, p. 75). Pressupõe-se a ausência de competição, uma vez que todos os potenciais fornecedores que preencham os requisitos poderão ser credenciados, caso assim tenham interesse. Além disso, é muito comum que o preço seja previamente estipulado pela Administração Pública no próprio edital de credenciamento, razão pela qual muitas vezes inexiste disputa com base em valores de lances, não havendo necessidade de competição para seleção da melhor proposta. É necessário apenas que os fornecedores preencham os requisitos básicos constantes no referido instrumento convocatório para que sejam credenciados. Torna-se fundamental também a existência de um critério objetivo para a seleção do particular que prestará o serviço ou que tal escolha não caiba à Administração, no momento da celebração de um contrato. Fernandes (2016, p. 1047) assim justifica o enquadramento, como hipótese de inexigibilidade de licitação, do credenciamento:

\footnotetext{
Se a Administração convoca todos os profissionais de determinado setor, dispondo-se a contratar todos os que tiverem interesse e que satisfaçam os requisitos estabelecidos, fixando ela própria o valor que se dispõe a pagar, os possíveis licitantes não competirão, no estrito sentido da palavra, inviabilizando a competição, uma vez que a todos foi assegurada a contratação.
}

Destaca-se que o TCU já se posicionou favoravelmente ao uso do sistema de credenciamento em reiteradas decisões. A Decisão n 656/1995 TCU-Plenário conclui que tal instituto atende aos princípios norteadores das licitações, em especial a legalidade, impessoalidade, isonomia, publicidade, probidade administrativa, vinculação ao instrumento convocatório e julgamento objetivo, e pode ser usado para o credenciamento de empresas e profissionais no ramo de saúde. A Decisão prevê os seguintes requisitos básicos para a sua utilização: 1) "dar 
ampla divulgação", com vistas a ampliar o universo dos credenciados; 2) "fixar os critérios e exigências mínimas para que os interessados possam credenciar-se", atentando-se para não incluir restrições indevidas; 3) "fixar, de forma criteriosa, a tabela de preços" que remunerará os diversos serviços, além de determinar as condições e os prazos para o pagamento dos serviços faturados; 4) incluir "vedação expressa do pagamento de qualquer sobretaxa em relação à tabela adotada"; 5) "estabelecer as hipóteses de descredenciamento", caso o credenciado não esteja cumprindo as regras e condições fixadas; 6) "permitir o credenciamento, a qualquer tempo, de qualquer interessado" que preencha os requisitos mínimos; 7) "prever a possibilidade de denúncia do ajuste, a qualquer tempo, pelo credenciado"; 8) "possibilitar que os usuários denunciem qualquer irregularidade verificada na prestação dos serviços"; e 9) "fixar as regras que devam ser observadas pelos credenciados no atendimento" (TCU, 1995, "grifo nosso").

Também o Acórdão n 784/2018 TCU-Plenário admite a utilização do instituto para contratação de prestação de serviços privados no âmbito do SUS, mas enfatiza a necessidade de que haja um preço pré-fixado pela Administração (TCU, 2018b). O Acórdão n 1150/2013 TCU-Plenário, por sua vez, reconhece a possibilidade de uso desse sistema para a contratação de serviços médicos, jurídicos e de treinamento, mas impõe o estabelecimento de critérios objetivos para a distribuição da demanda entre os credenciados e para a fixação de um preço compatível com o de mercado para a remuneração do serviço (TCU, 2013). Já o Acórdão $n^{\circ}$ 351/2010 TCU-Plenário faculta o uso do instituto para credenciamento de agricultores visando ao suprimento de gêneros alimentícios às organizações militares distribuídas na Amazônia Ocidental. Ressalta, entretanto, que é imprescindível a "garantia da igualdade de condições entre todos os interessados hábeis a contratar com a Administração, pelo preço por ela definido" (TCU, 2010).

Por fim, o Acórdão n 1191/2018 TCU-Plenário permite o uso do credenciamento na contratação de instituições financeiras para o pagamento da remuneração de servidores públicos (TCU, 2018b). Na verdade, os serviços bancários também podem ser objeto de credenciamento nessas situações, porque, assim como no caso de médicos e advogados, fica a encargo do usuário final do serviço a escolha de qual banco deseja utilizar para o recebimento do seu salário, dentre todos os credenciados. É necessário, não obstante, que a Administração Pública fixe os critérios mínimos a serem cumpridos pelas instituições financeiras interessadas em fornecer o serviço e permita o credenciamento de todas aquelas que preencham os pré-requisitos. 
Cumpre enfatizar que no credenciamento não há obrigatoriedade de contratação de todos os credenciados. Há apenas a necessidade de que se abra a possibilidade de credenciamento para os interessados que preencham os requisitos mínimos e de que todos os credenciados tenham condições similares de serem contratados. Esse é o entendimento de Justen Filho (2014, p. 40):

Note-se que a Administração não determina, de antemão, quais profissionais serão consultados e prestarão serviços. Nada impede que um profissional credenciado seja o único escolhido por todos os beneficiários e que outros não sejam procurados por quem quer que seja.

O instituto ora discutido é frequentemente utilizado por entidades de governos estaduais para o credenciamento de médicos e hospitais privados, uma vez que nesse tipo de contratação usualmente não há disputa, mas sim a possibilidade de aproveitamento de quaisquer fornecedores registrados. Além disso, quem escolherá qual médico ou hospital deseja utilizar será o beneficiário direto do serviço, e não a própria Administração. Observa-se, inclusive, que o credenciamento, apesar de não possuir previsão legal expressa em âmbito federal, encontra menção em diversos instrumentos normativos estaduais. É o caso, por exemplo, da Lei do estado de Goiás $n^{\circ}$ 17.928, de 27 de dezembro de 2012, que prevê, em seu art. $2^{\circ}$, inciso $\mathrm{X}$, a possibilidade de utilização do credenciamento para contratação de serviços "nas hipóteses em que a multiplicidade de fornecedores simultâneos melhor atenda o interesse público" (Goiás, 2012).

Também a Lei do estado da Bahia $n^{\circ} 9.433$, de $1^{\circ}$ de março de 2005 , admite a utilização do credenciamento por inviabilidade de competição e comanda, em seu art. 62, que a Administração garanta o "tratamento isonômico aos interessados, com o acesso permanente a qualquer um que preencha as exigências estabelecidas em regulamento". Fala-se também, dentre os requisitos para o uso do instituto, da "fixação criteriosa da tabela de preços que remunerará os serviços a serem prestados" (Bahia, 2005).

A Lei do estado do Paraná $n^{\circ} 15.608$, de 16 de agosto de 2007, define o credenciamento como ato administrativo de chamamento público por edital, que pode ser adotado pela Administração Estadual "para situações em que o mesmo objeto possa ser realizado simultaneamente por diversos contratados" (art. 24, parágrafo único). $\mathrm{O}$ art. 25 dessa Lei elenca os requisitos para o uso do credenciamento, que são similares aos elementos presentes na Decisão n 656/1995 TCU-Plenário, acima transcritos. Fala-se também da necessidade de "rotatividade entre todos os credenciados, sempre excluída a vontade da Administração na 


\section{determinação da demanda por credenciado" (inciso V). O parágrafo segundo do artigo também traz a exigência de fixação a priori do valor a ser pago pela Admi- nistração pelos serviços (Paraná, 2007).}

\section{Tabela 1 - Exemplos da previsão do sistema de credenciamento em legislações estaduais}

\begin{tabular}{|c|c|c|c|}
\hline Estado & Paraná & Bahia & Goiás \\
\hline $\begin{array}{l}\text { Instrumento } \\
\text { Legal }\end{array}$ & $\begin{array}{l}\text { Lei } n^{\circ} 15.608 \text {, de } 16 \text { de agosto } \\
\text { de } 2007\end{array}$ & $\begin{array}{l}\text { Lei } n^{\circ} 9.433 \text {, de } 01 \text { de março de } \\
2005\end{array}$ & $\begin{array}{l}\text { Lei } n^{\circ} 17.928 \text {, de } 27 \text { de dezembro } \\
\text { de } 2012\end{array}$ \\
\hline $\begin{array}{l}\text { Definição do } \\
\text { instituto }\end{array}$ & $\begin{array}{l}\text { Art. 24. Credenciamento é ato } \\
\text { administrativo de chamamen- } \\
\text { to público, processado por } \\
\text { edital, destinado à contrata- } \\
\text { ção de serviços junto àqueles } \\
\text { que satisfaçam os requisitos } \\
\text { definidos pela Administração, } \\
\text { observado o prazo de publici- } \\
\text { dade de no mínimo } 15 \text { (quin- } \\
\text { ze) dias úteis e no máximo de } \\
30 \text { (trinta) dias úteis. } \\
\text { Parágrafo único. A Adminis- } \\
\text { tração Estadual poderá ado- } \\
\text { tar o credenciamento para } \\
\text { situações em que o mesmo } \\
\text { objeto possa ser realizado si- } \\
\text { multaneamente por diversos } \\
\text { contratados. }\end{array}$ & $\begin{array}{l}\text { Art. 61. É inexigível a licitação, } \\
\text { por inviabilidade de competição, } \\
\text { quando, em razão da natureza } \\
\text { do serviço a ser prestado e da } \\
\text { impossibilidade prática de se } \\
\text { estabelecer o confronto entre os } \\
\text { interessados, no mesmo nível } \\
\text { de igualdade, certas necessida- } \\
\text { des da Administração possam } \\
\text { ser melhor atendidas mediante } \\
\text { a contratação do maior número } \\
\text { possível de prestadores de ser- } \\
\text { viço, hipótese em que a Adminis- } \\
\text { tração procederá ao credencia- } \\
\text { mento de todos os interessados } \\
\text { que atendam às condições esta- } \\
\text { belecidas em regulamento. }\end{array}$ & $\begin{array}{l}\text { Art. } 2^{\circ} \text { Para os fins desta Lei, ado- } \\
\text { tar-se-ão as definições da legisla- } \\
\text { ção federal pertinente, às quais se } \\
\text { acrescentam as seguintes: } \\
\text { (...) } \\
\text { IX - sistema de credenciamento } \\
\text { - é o conjunto de procedimentos } \\
\text { por meio dos quais a Administra- } \\
\text { ção credencia, mediante chama- } \\
\text { mento público, os fornecedores e/ } \\
\text { ou prestadores de determinados } \\
\text { bens ou serviços, nas hipóteses } \\
\text { em que a multiplicidade de forne- } \\
\text { cedores simultâneos melhor aten- } \\
\text { da o interesse público. }\end{array}$ \\
\hline
\end{tabular}




\begin{tabular}{|c|c|c|c|}
\hline $\begin{array}{l}\text { Requisitos } \\
\text { para sua utili- } \\
\text { zação }\end{array}$ & 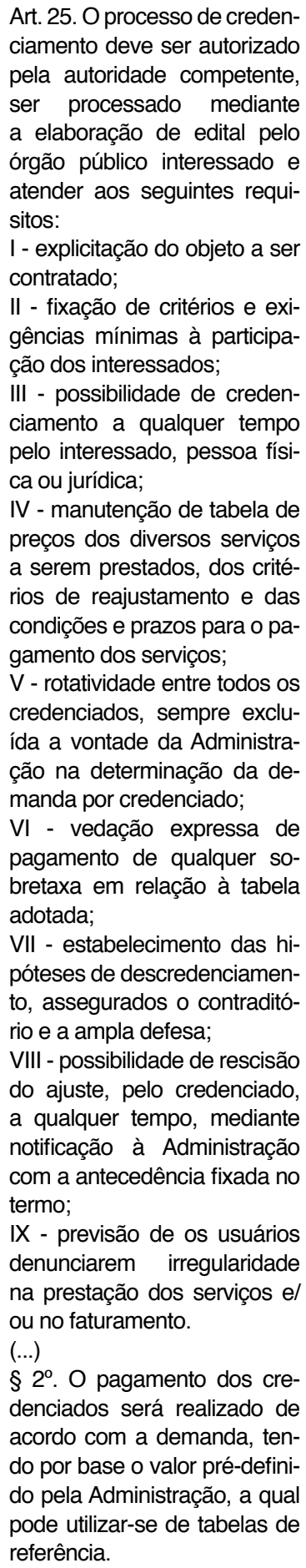 & $\begin{array}{l}\text { Art. 62. Na implantação de um } \\
\text { sistema de credenciamento, a } \\
\text { Administração deverá preservar } \\
\text { a lisura, transparência e eco- } \\
\text { nomicidade do procedimento e } \\
\text { garantir tratamento isonômico } \\
\text { aos interessados, com o acesso } \\
\text { permanente a qualquer um que } \\
\text { preencha as exigências estabe- } \\
\text { lecidas em regulamento, deven- } \\
\text { do instruir o respectivo processo } \\
\text { com os seguintes elementos: } \\
\text { I - convocação dos interessados } \\
\text { por meio do Diário Oficial do Es- } \\
\text { tado, de jornal de grande circula- } \\
\text { ção e, sempre que possível, por } \\
\text { meio eletrônico; } \\
\text { II - fixação criteriosa da tabela de } \\
\text { preços que remunerará os servi- } \\
\text { ços a serem prestados; } \\
\text { III - regulamentação da sistemá- } \\
\text { tica a ser adotada. }\end{array}$ & 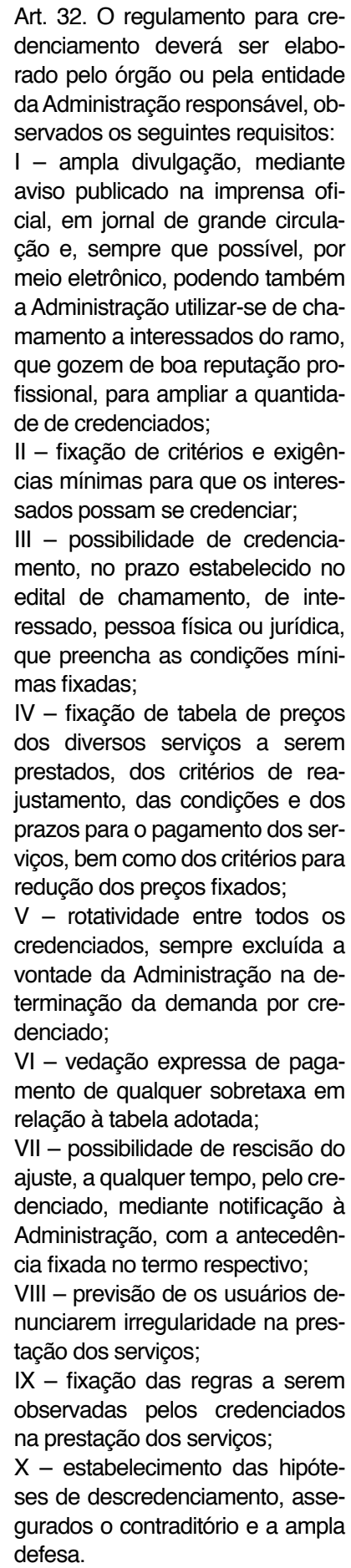 \\
\hline
\end{tabular}

Fonte: Bahia, 2005; Paraná, 2007; Goiás, 2012.

Fernandes (2016, p. 1048-1049) assim sumariza os principais aspectos para a implementação do sistema de credenciamento: 
(i) possibilidade de contratação de todos os que satisfaçam às condições exigidas;

(ii) que a definição da demanda por contratado não seja feita pela Administração;

(iii) que o objeto satisfaça à Administração, desde que executado na forma definida no edital;

(iv) que o preço de mercado seja razoavelmente uniforme, e que a fixação prévia de valores seja mais vantajosa para a Administração (Fernandes, 2016, p. 1048-1049).

No que diz respeito ao impedimento de que a demanda por contratado seja definida pela própria Administração, Fernandes (2016, p. 1048) assevera que "a jurisprudência já consagrou pelo menos três possibilidades de uso do credenciamento, mas sempre excluindo a vontade da Administração na determinação da demanda por credenciado". Conforme o referido autor, o TCU já aceitou que a escolha seja feita pelo próprio servidor, no caso de serviço médico e de treinamento, e que seja por sorteio aleatório entre todos os credenciados, excluindo-se sempre os sorteados anteriormente, para o caso de serviços advocatícios.

A tabela 2 resume as principais vantagens e limitações do sistema de credenciamento, conforme os pontos discutidos nesta seção:

Tabela 2 - Principais vantagens e desvantagens do sistema do credenciamento

\begin{tabular}{|cc|}
\hline $\begin{array}{c}\text { Após a fase inicial de credenciamento dos } \\
\text { fornecedores interessados, o processo de } \\
\text { contratação torna-se ágil. }\end{array}$ & $\begin{array}{c}\text { O credenciamento exige a apresentação de } \\
\text { documen-tação dos particulares interessados na } \\
\text { fase inicial, de modo que comprovem o }\end{array}$ \\
$\begin{array}{c}\text { Possibilidade de credenciamento de uma gama } \\
\text { significativa de fornecedores interessados em } \\
\text { prestar serviços para a Administração Pública. }\end{array}$ & $\begin{array}{c}\text { preenchimento dos requisitos constantes no edital, } \\
\text { o que pode gerar certa morosidade e custos } \\
\text { adicionais para os particulares. }\end{array}$ \\
$\begin{array}{c}\text { Não exige a implementação de uma plataforma } \\
\text { tecnológica complexa para a sua utilização. }\end{array}$ & $\begin{array}{c}\text { Diversas legislações estaduais e entendimentos } \\
\text { jurisprudenciais e doutrinários tendem a restringir o } \\
\text { seu uso à contratação de serviços. }\end{array}$ \\
$\begin{array}{c}\text { Custo administrativo tende a ser menor do que } \\
\text { a realização de um procedimento licitatório } \\
\text { pelas modalidades existentes no ordenamento } \\
\text { jurídico brasileiro. }\end{array}$ & $\begin{array}{c}\text { Preço fixado a priori pela Administração Pública, } \\
\text { ine-xistindo pressão e competição para redução de } \\
\text { preços entre os fornecedores credenciados. }\end{array}$ \\
& Possibilidade de uso apenas na hipótese de \\
inexigibilidade de licitação.
\end{tabular}

Fonte: elaborado pelo autor.

Com relação à tabela 2, é interessante frisar que as legislações estaduais e decisões do TCU acima referenciadas restringem o uso do credenciamento à contratação de serviços. Não obstante, entende-se que não há, em âmbito federal, vedação a uma possível utilização do credenciamento para a aquisição de produtos. Nesse sentido, cumpre enfatizar que o Projeto de Lei $n^{\circ} 1.292$, de 30 de novembro de 1995, que se propõe a substituir a atual Lei ${ }^{\circ} 8.666 / 1993$, em sua redação final de 17 de setembro de 2019, permite o uso do credenciamento tam- 
bém para a compra de produtos, e não apenas para a aquisição de serviços, ao definir o instituto como "processo administrativo de chamamento público em que a Administração Pública convoca interessados em prestar serviços ou fornecer bens para que, preenchidos os requisitos necessários, credenciem-se no órgão ou na entidade para executar o objeto quando convocados" (artigo $5^{\circ}$, inciso XLII, "grifo nosso") (Brasil, 1995).

Ainda em relação ao referido Projeto de Lei, é interessante ressaltar que se encontram previstas em seu art. 70 três hipóteses de uso do credenciamento. Observa-se que, em duas delas, o dispositivo legal compele a Administração a definir de antemão o valor a ser remunerado pela prestação do objeto da contratação no instrumento de convocação. Entretanto, para um dos casos de uso, não há tal exigência de prefixação de valores remuneratórios. É a hipótese de contratação em mercados fluidos, "caso em que a flutuação constante do valor da prestação e das condições de contratação inviabiliza a seleção de agente por meio do procedimento de licitação" (Brasil, 1995). É certo que se trata de um Projeto de Lei que atualmente aguarda apreciação pelo Senado Federal, mas essa redação do dispositivo parece indicar que há uma tendência em reconhecer a possibilidade de ampliação do uso do instituto de credenciamento de forma mais flexível, para que se torne uma ferramenta mais eficiente, de modo a permitir contratações mais simples e ágeis, como no estudo de caso descrito na seção a seguir.

$\mathrm{Na}$ verdade, dentre as desvantagens acima apontadas, a necessidade de fixação prévia do valor a ser remunerado pela Administração Pública configura-se como o principal ponto negativo do credenciamento. Essa restrição tende a reduzir a eficiência do instituto, uma vez que restringe a pressão pela redução dos valores pagos pela Administração. Por outro lado, teme-se que a não fixação do valor da remuneração de antemão possa minar um dos requisitos para a configuração do credenciamento como hipótese de inexigibilidade. O Projeto de Lei acima destacado apresenta um caso de possível utilização do credenciamento sem fixação a priori do valor do pagamento. O presente artigo também defende que é possível flexibilizar a necessidade dessa pré-estipulação do quantum remuneratório a ser pago aos credenciados, apresentando como exemplo o modelo de credenciamento de companhias aéreas descrito na seção a seguir. 


\section{O MODELO DE CREDENCIAMENTO DE COMPANHIAS AÉREAS DESEN- VOLVIDO PELA CENTRAL DE COMPRAS}

A Central de Compras desenvolveu um modelo de credenciamento para a aquisição de passagens de avião diretamente das companhias aéreas, sem necessidade de intermediação de agências de turismo, como forma de agilizar o processo de compra e reduzir o valor pago pelas passagens (Miranda, 2018). Observou-se que o credenciamento poderia ser utilizado para esse objeto porque o número de companhias aéreas em operação no Brasil é facilmente identificável, representando um universo limitado de empresas. Por essa razão, foi possível que a Central de Compras interagisse diretamente com todos os possíveis fornecedores e credenciasse a integralidade dos interessados que preenchessem os pré-requisitos.

Inicialmente, cumpre enfatizar que esse modelo, apesar de ter funcionado de forma adequada e eficiente em anos anteriores, encontra-se atualmente suspenso em função de um entrave legal que será discutido mais à frente nesta seção. Dessa forma, enquanto esse empecilho legal está sendo sanado, os órgãos da Administração Pública estão temporariamente realizando a aquisição de passagens aéreas com a intermediação de agências de turismo. Assim, este estudo de caso descreve a maneira como o modelo encontrava-se em funcionamento em 2019, como forma de explorar uma aplicação flexível e eficaz do instituto do credenciamento. Ressalta-se, entretanto, que, apesar de suspenso, o projeto está ativo, sendo redesenhado para reinício de sua implementação.

Para a operacionalização do modelo, a Central de Compras entrou em contato com todas as companhias que operam no país e realizou o credenciamento. Naturalmente, foram realizadas negociações entre a Central de Compras e as companhias aéreas, pois, ao mesmo tempo que se buscava um modelo capaz de atender aos interesses da Administração Pública, mostrava-se igualmente importante entender a forma de operação das empresas nesse setor, a fim de que o sistema implementado não fosse conflitante com as práticas usuais de mercado.

Nesse sentido, cabe apontar algumas dificuldades enfrentadas no momento da negociação. A primeira delas foi em relação à forma de pagamento dos fornecedores. A Administração Pública possui uma reputação no mercado de frequentemente atrasar os pagamentos de seus fornecedores, e as companhias aéreas não aceitariam um modelo no qual precisassem esperar por semanas ou até meses para receber a remuneração por seus serviços. Essa questão foi resolvida por meio do uso do Cartão de Pagamento do Governo Federal (CPGF) para a aquisição das passagens aéreas, uma vez que constitui um meio de pagamento ágil. 
Conforme Daly e Buehner (2003, p. 92), o uso de cartões de pagamentos em compras públicas apresenta potenciais vantagens fiscais e financeiras, além de possibilitar a simplificação do processo de remuneração dos fornecedores e conferir maior discricionariedade aos servidores públicos, quando na qualidade de usuários finais de um serviço. O uso do CPGF no âmbito do projeto desenvolvido pela Central de Compras também obteve resultados satisfatórios em termos de simplificação e agilidade do pagamento, além de proporcionar controle dos gastos.

O segundo problema enfrentado foi em relação à obrigatoriedade, constante na legislação brasileira, de que o governo retenha os tributos antes de realizar o repasse do pagamento aos seus fornecedores. Tendo em vista que o sistema tributário no Brasil é complexo, possuindo diversos tipos de tributos com diferentes alíquotas, que muitas vezes variam de acordo com o ente federado, é difícil desenvolver um sistema que consiga calcular e reter automaticamente os tributos antes de realizar o pagamento no caso das passagens aéreas. Além disso, observa-se que o preço de uma passagem aérea também inclui tarifas de embarque e de aeroportos, o que dificultaria ainda mais o cálculo do tributo a ser retido. Esse problema foi contornado temporariamente com a edição da Medida Provisória ${ }^{\circ}$ 877, de 25 de março de 2019, que dispensava a retenção dos tributos na fonte sobre os pagamentos efetuados por órgãos da Administração Pública, mediante a utilização do CPGF, "no caso de compra de passagens aéreas diretamente das companhias aéreas prestadoras de serviços de transporte aéreo" (Brasil, 2019). Entretanto, esse problema precisa agora ser reanalisado em função da não conversão da referida Medida Provisória em lei pelo Congresso Nacional, razão pela qual o uso do modelo se encontra temporariamente suspenso no âmbito da Central de Compras. Atualmente, está em discussão na Câmara dos Deputados o Projeto de Lei $n^{\circ}$ 10.060/2018 (Brasil, 2018), que dispõe sobre o uso do CPGF por todos os Poderes e órgãos da União e pode ser um caminho para solucionar o atual empecilho enfrentado pelo modelo de credenciamento de passagens aéreas. Entretanto, também já se encontra em etapa avançada o estudo de uma forma alternativa de colocá-lo novamente em funcionamento, sem depender da edição de medidas provisórias ou leis.

De todas as companhias aéreas contatadas pela Central de Compras, destaca-se que apenas duas delas, em um momento inicial, não foram credenciadas. Entretanto, é fundamental frisar que isso ocorreu em função da ausência da apresentação de documentos de habilitação necessários por parte das companhias e não por alguma restrição imposta pela Administração. Dessa forma, logrou-se 
garantir o principal requisito do instituto do credenciamento: a possibilidade de credenciar todos os fornecedores interessados na prestação do serviço que preencham os requisitos necessários, como forma de enquadramento na hipótese de inexigibilidade de licitação.

Além disso, foi também publicada a Instrução Normativa $n^{\circ} 03$, de 11 de fevereiro de 2015, pela então Secretaria de Logística e Tecnologia da Informação e Comunicação do Ministério do Planejamento, Orçamento e Gestão. Em seu art. 16, a referida Instrução Normativa define os parâmetros para a escolha da passagem aérea a ser adquirida, incluindo, por exemplo, a necessidade de que os voos recaiam prioritariamente em percursos de menor duração e cujos horários de partida e chegada estejam compreendidos entre $7 \mathrm{~h} 00$ e $21 \mathrm{~h} 00$. O parágrafo único do artigo prevê que "a escolha da tarifa deve privilegiar o menor preço, prevalecendo, sempre que possível, a tarifa em classe econômica" (Brasil, 2015).

A aquisição das passagens é realizada por meio de um sistema do próprio Ministério, denominado Sistema de Concessão de Diárias e Passagens (SCDP), que acessa os tickets disponíveis na hora da busca com os preços praticados no mercado. Com base nas opções presentes no momento do acesso, é analisado primeiramente quais atendem aos parâmetros constantes no art. 16 da mencionada Instrução Normativa, e só depois avaliam-se as alternativas remanescentes em relação ao preço. Destaca-se que o servidor, em um momento inicial, não tem acesso ao nome das companhias aéreas disponíveis e somente alimenta o sistema com dados como o horário que pretende viajar, o quão flexível é seu calendário, se possui restrição de viagem em algum período do dia etc. Com base nos parâmetros da Instrução Normativa e nas informações incluídas pelo servidor sobre as necessidades peculiares de sua viagem de trabalho, o sistema gera as opções de passagem que poderão ser escolhidas. Ao final do processo, a orientação do normativo, conforme já referenciado, é de que a escolha seja pela passagem de menor preço. O servidor pode vir a optar por uma passagem mais cara, mas deverá justificar tal decisão, por escrito, no momento da compra.

O processo de credenciamento das companhias aéreas já foi analisado pelo TCU, que se posicionou favoravelmente ao modelo por intermédio do Acórdão $\mathrm{n}^{\circ}$ 1545/2017 TCU-Plenário. Neste contexto, é conveniente apresentar um exemplo de que o modelo desenvolvido pela Central de Compras de fato incorporou as necessidades das empresas. Constata-se que, no item 107 do referido Acórdão, existe uma sugestão de que o sistema eletrônico utilizado para a compra de passagens aéreas realize, pouco antes do voo, uma nova busca, para averiguar se 
não há uma outra passagem disponível com valor menor ao daquela já adquirida pela Administração Pública (TCU, 2017). A Central de Compras, entretanto, não adotou a referida sugestão por ser inviável sob o ponto de vista das companhias aéreas, uma vez que não se coaduna com as práticas usuais de mercado do setor. Afirmou-se, durante as entrevistas, que o mercado de tickets aéreos possui uma estrutura própria de descontos, em que as primeiras passagens são vendidas com preços mais atrativos, as seguintes são mais caras, e assim sucessivamente. É certo que cancelamentos de última hora resultam no surgimento de passagens mais baratas, mas se a Administração Pública permitisse que o servidor alterasse o voo sucessivamente em busca de menores preços e incorporasse essa alternativa no seu modelo de credenciamento, tornaria o sistema não atrativo às companhias aéreas, por ser contrário às práticas de precificação desse mercado.

A experiência do sistema de passagens aéreas demonstra que é possível utilizar-se do sistema de credenciamento de uma forma mais flexível, permitindo que, após credenciar todas as empresas interessadas em prestar serviços à Ad-ministração Pública, seja realizada uma análise dos preços disponíveis no mer-cado no momento da compra efetiva pelo servidor, usuário final do serviço, antes de adquirir o serviço de um dos credenciados. O modelo foi eficaz em reduzir os custos relacionados à intermediação por agências de turismo, uma vez que a Ad-ministração passou a utilizar um sistema eletrônico permitindo a compra direta das companhias aéreas. Além disso, com o sistema de busca no momento da compra, tornou-se viável a aquisição do bilhete aéreo em um preço compatível ao valor de mercado. Conforme assevera Miranda (2018, p. 9-10), tal modelo de compra direta de passagens aéreas resultou em redução aproximada de $20 \%$ no tempo de emissão do bilhete aéreo a partir de sua solicitação e um percentual médio de economicidade de 22,43\% em 2015, $17,28 \%$ em 2016 e 16,28\% em 2017.

\section{CONCLUSÃO}

O modelo de credenciamento de companhias aéreas para a aquisição de passagens no âmbito da Administração Pública Federal apresentado neste artigo parece indicar que alguns elementos apontados pela doutrina, jurisprudência e até mesmo constantes em legislações estaduais não constituem requisitos essenciais para a implementação de tal instituto. Em especial, observa-se que nem todos os casos de credenciamento 
impõem a obrigatoriedade de fixação a priori de valores remuneratórios pela Administração em um instrumento convocatório. Além disso, embora o instituto seja amplamente utilizado para a contratação de serviços, não há de se falar em proibição de seu uso para a aquisição de bens. Entende-se, portanto, que os únicos elementos realmente fundamentais do sistema de credenciamento são aqueles indispensáveis para o seu enquadramento na hipótese de inexigibilidade de licitação, ou seja: (i) a possibilidade de que todos os particulares que preencham os requisitos exigidos sejam credenciados; (ii) a existência de um número ilimitado de potenciais contratações; (iii) a possibilidade de que qualquer dos credenciados venha a ser efetivamente contratado; e (iv) a existência de um critério objetivo e imparcial para a escolha do credenciado, ou que essa escolha não recaia sobre a Administração.

O modelo apresentado neste artigo revela a possibilidade de utilização do sistema de credenciamento para imprimir maior agilidade e eficiência ao processo público de aquisição. Não obstante, observa-se que o credenciamento de companhias aéreas possui certas peculiaridades que podem ser de difícil identificação em outros nichos de mercado. Em particular, destaca-se que o mercado nacional de passagens aéreas é caracterizado por um número limitado e facilmente identificável de empresas atuantes, o que facilita o processo de mapeamento de todas as companhias que poderiam ser consideradas potenciais prestadoras de serviço nesse ramo. Segundo a ANAC (2018, p. 20), apenas 4 empresas respondiam por mais de $99 \%$ dos transportes de passageiros no Brasil em 2017. Assim, esse modelo, especialmente no que tange à realização de uma minicompetição entre os fornecedores ou de uma busca online por menores preços no momento da aquisição do serviço, poderia ser de difícil implementação em um segmento de mercado no qual exista grande quantidade de fornecedores.

Pode-se identificar, portanto, os seguintes fatores que contribuíram para os resultados positivos do sistema de credenciamento de companhias aéreas discutido neste artigo: (i) existência de um número limitado e identificável de fornecedores; (ii) possibilidade de que todos esses fornecedores sejam credenciados; (iii) mecanismos que minimizem a 
formação de conluios entre credenciados, aqui caracterizado pelo serviço de busca online no momento da aquisição da passagem; e (iv) realização de minicompetições ou possibilidade de comparação online de preços atualizados de mercado no momento da seleção do fornecedor para a efetiva contratação.

Entende-se que são relevantes iniciativas direcionadas a promover utilizações mais flexíveis do credenciamento, desde que sempre procurem manter o seu enquadramento dentro das possibilidades legais de contratação admitidas pelo ordenamento jurídico brasileiro. Particularmente, há a necessidade, ainda que se leve em conta as restrições desse instituto por ser considerado uma hipótese de inexigibilidade de licitação, de procurar incluir maior competição ou, ao menos, maior pressão por melhores condições de preço e de fornecimento do objeto da contratação por parte dos fornecedores credenciados.

Nesse sentido, mostram-se de grande importância tentativas de se aproximar o credenciamento de procedimentos de agregação de demanda utilizados em outros países, como o Acordo-Quadro, bastante usual em países como Chile, Itália e Reino Unido. Em linhas gerais, no âmbito do Acordo-Quadro, a entidade centralizadora publica um edital com informações gerais sobre as condições de contratação e especificações do bem ou serviço a ser adquirido e realiza o cadastramento de empresas interessadas em se tornarem fornecedoras do governo para tal objeto. No momento que um órgão deseja realizar um certame, ele executa uma minicompetição entre as empresas cadastradas, apresentando um maior detalhamento das especificações e condições do bem ou serviço a ser contratado, e formaliza a contratação com o ganhador da minicompetição. $\mathrm{Na}$ verdade, Fiuza, Pompermayer e Rauen (2019, p. 105) consideram a necessidade de fixação de preço a priori e a dificuldade de se realizar uma minicompetição para adjudicação de contratos como alguns dos principais pontos que distanciam o credenciamento dos Acordos-Quadros.

Dentre as potenciais vantagens dos Acordos-Quadros apresentadas por Albano e Nicholas (2016, p 22-30), destacam-se as seguintes: (i) aumento da eficiência administrativa, em função da redução do tempo e dos custos administrativos com a negociação centralizada de contratações anteriormente pulverizadas; (ii) eficiência do processo, a partir da minimização do custo 
transacional e do uso por diversos órgãos de um mesmo procedimento padronizado, desenvolvido pelo órgão centralizador; (iii) melhor desempenho das compras em situações emergenciais e prevenção do uso de licitações de caráter excepcional em casos de urgência, uma vez que já existirão fornecedores previamente cadastrados no âmbito de um Acordo-Quadro; (iv) melhor desempenho de licitações envolvendo pequenos valores, pois a existência de mecanismos como o Acordo-Quadro pode evitar aquisições de bens de baixa qualidade ou com preço superior ao valor de mercado nas hipóteses de compras diretas permitidas por lei; (v) garantia da segurança do fornecimento, pois o Acordo-Quadro vincula os fornecedores cadastrados a abastecerem os órgãos, caso exista demanda; e (vi) aumento da competição por intermédio da agregação da demanda, o que pode resultar em redução do preço final do bem ou serviço em função da economia de escala.

É certo que existem diferenças entre a legislação brasileira de compras públicas e a dos países que adotam os referidos AcordosQuadros, o que impede a implementação de uma contratação pública pelo credenciamento da mesma forma que se opera uma aquisição por meio de Acordo-Quadro. Entretanto, é fundamental que se avalie os pontos convergentes, para que se possa utilizar o credenciamento de forma mais eficiente para os nichos de mercado nos quais se observe a possibilidade de aplicação mais flexível e inovadora do referido instituto. Futuros estudos que se dediquem a essa questão serão de grande relevância, tanto acadêmica quanto prática, para a área de políticas públicas.

\section{REFERÊNCIAS}

Agência Nacional de Aviação Civil (ANAC). (2018). Anuário do Transporte Aéreo 2017. Brasília: ANAC.

Albano, G. L., \& Nicholas, C. (2016). The Law and Economics of Framework Agreements: Designing Flexible Solutions for Public Procurement. Cambridge: Cambridge University Press.

Anderson, R. D., Kovacic, W., \& Müller, A. C. (2012). Ensuring integrity and competition in public procurement markets: a dual challenge for good governance. In: Escritório das Nações Unidas para Serviços de Projetos (UNOPS). (2012). Transparency and public procurement, Supplement to the $2011 \mathrm{An}$ nual Statistical Report on United Nations Procurement. UNOPS. 
Bahia. (2005). Lei $n^{\circ}$ 9.433, de 01 de março de 2005. Dispõe sobre as licitações e contratos administrativos pertinentes a obras, serviços, compras, alienações e locações no âmbito dos Poderes do Estado da Bahia e dá outras providências. Estado da Bahia, Casa Civil. Recuperado de http://www.legislabahia. ba.gov.br/documentos/lei-no-9433-de-01-de-marco-de-2005.

Brasil. (1993). Lei.$^{\circ}$ 8.666, de 21 de junho de 1993. Regulamenta o art. 37, inciso $\mathrm{XXI}$, da Constituição Federal, institui normas para licitações e contratos da Administração Pública e dá outras providências. Presidência da República, Casa Civil, Subchefia para Assuntos Jurídicos. Recuperado de http://www. planalto.gov.br/ccivil_03/leis//8666cons.htm.

Brasil. (1995). Câmara dos Deputados. Projeto de Lei $n^{\circ}$ 1.292, de 30 de novembro de 1995. Estabelece normas gerais de licitação e contratação para as administrações públicas diretas, autárquicas e fundacionais da União, dos Estados, do Distrito Federal e dos Municípios; altera as Leis ns 13.105, de 16 de março de 2015 (Código de Processo Civil), 8.987, de 13 de fevereiro de 1995, e 11.079, de 30 de dezembro de 2004, e o Decreto-Lei $n^{\circ} 2.848$, de 7 de dezembro de 1940 (Código Penal); e revoga dispositivos da Lei $n^{\circ}$ 12.462, de 4 de agosto de 2011, e as Leis $n^{\circ} 8.666$, de 21 de junho de 1993, e 10.520, de 17 de julho de 2002. Recuperado de https://www.camara.leg. $\mathrm{br} /$ proposicoesWeb/fichadetramitacao?idProposicao $=16526$.

Brasil. (2015). Secretaria de Logística e Tecnologia da Informação do Ministério do Planejamento, Desenvolvimento e Gestão. Instrução Normativa ${ }^{\circ}{ }^{\circ}$, de 11 de fevereiro de 2015. Governo Federal, Portal de Compras. Recuperado de https://www.comprasgovernamentais.gov.br/index.php/legislacao/instrucoes-normativas/297-instrucao-normativa-n-3-de-11-de-fevereiro-de-2015.

Brasil. (2018). Câmara dos Deputados. Projeto de Lein ${ }^{\circ}$ 10060/2018, de 18 de abril de 2018. Dispõe sobre o uso do Cartão de Pagamentos de Gastos Federais (CPGF) por todos os Poderes e órgãos da União. Recuperado de https://www. camara.leg.br/proposicoesWeb/fichadetramitacao?idProposicao=2172484.

Brasil. (2019). Medida Provisória $n^{\circ}$ 877, de 25 de março de 2019. Altera a Lei $\mathrm{n}^{\circ}$ 9.430, de 27 de dezembro de 1996, para dispor sobre a dispensa de retenção de tributos federais na aquisição de passagens aéreas pelos órgãos ou pelas entidades da Administração Pública Federal. Presidência da República, Casa Civil, Subchefia para Assuntos Jurídicos. Recuperado de http://www.planalto.gov.br/ccivil_03/_Ato2019-2022/2019/Mpv/mpv877. htm\#: :text=MEDIDA\%20PROVIS\%C3\%93RIA\%20N\%C2\%BA\%20 
877\%2C\%20DE\%2025\%20DE\%20MAR\%C3\%870\%20DE\%202019\&tex$\mathrm{t}=$ Altera $\% 20 \mathrm{a} \% 20 \mathrm{Lei} \% 20 \mathrm{n} \% \mathrm{C2} \% \mathrm{BA} \% 209.430$,entidades\%20da\%20 administra\%C3\%A7\%C3\%A30\%20p\%C3\%BAblica\%20federal.

Daly, J. L., \& Buehner, M. A. (2003). P-card Utilization in Municipal Government: Advantages and Concerns. Journal of Public Procurement, 3(1), 75-94.

Fernandes, J. U. J. (2016). Vade-mécum de licitações e contratos. (7. ed.) Belo Horizonte: Fórum.

Fiuza, E. P. S., Pompermayer, F. M., \& Rauen, A. T. (2019) A Retomada da Agenda Perdida das Compras Públicas: Notas Sobre o Novo Projeto de Lei de Licitações da Câmara dos Deputados em 2018-2019. Nota Técnica n. 47, Instituto de Pesquisa Econômica Aplicada. Recuperado de http://www.ipea. gov.br/portal/images/stories/PDFs/nota_tecnica/190322_nt_47_diset.pdf.

Gerring, J. (2007). Case Study Research: Principles and Practices. Cambridge: Cambridge University Press.

Gillham, B. (2000). Case Study Research Methods. Londres: Continuum.

Goiás. (2012). Lei $n^{\circ}$ 17.928, de 27 de dezembro de 2012. Dispõe sobre normas suplementares de licitações e contratos pertinentes a obras, compras e serviços, bem como convênios, outros ajustes e demais atos administrativos negociais no âmbito do Estado de Goiás. Estado de Goiás. Secretaria de Estado da Casa Civil. Recuperado de https://legisla.casacivil.go.gov.br/ pesquisa_legislacao/89895/lei-17928.

Guimarães, B. S. (2016). Credenciamento e Contratos da Administração: uma alternativa virtuosa. Direito do Estado, 27 de junho de 2016. Recuperado de http://www.direitodoestado.com.br/colunistas/bernardo-strobel-guimaraes/ credenciamento-e-contratos-da-administracao-uma-alternativa-virtuosa.

Justen Filho, M. (2004). Comentários à lei de licitações e contratos administrativos. (10. ed.). São Paulo: Dialética.

Marconi, M. de A., \& Lakatos, E. M. (2003). Fundamentos de metodologia científica. (5. ed.) São Paulo: Atlas.

Medauar, O. (2018). Direito administrativo moderno. (21. ed.). Belo Horizonte: Fórum Conhecimento Jurídico.

Mills, A. J., Eurepos, G., \& Wiebe, E. (2010) Encyclopedia of Case Study Research. California: Sage.

Miranda, H. S. (2018). Compra direta de passagens aéreas. Enap. Casoteca de Gestão Pública. Recuperado de https://repositorio.enap.gov.br/bitstream/1/3460/7/Compra\%20direta\%20de\%20passagens\%20a\%C3\%A9reas_ portugu\%C3\%AAs.pdf. 
Paraná. (2007). Lei $n^{\circ} 15.608$, de 16 de agosto de 2007. Estabelece normas sobre licitações, contratos administrativos e convênios no âmbito dos Poderes do Estado do Paraná. Estado do Paraná, Casa Civil, Sistema Estadual de Legislação. Recuperado de https://www.legislacao.pr.gov.br/legislacao/listarAtosAno.do?action=exibir\&codAto=5844\&indice=4\&totalRegistros=407\&anoSpan=2010\&anoSelecionado=2007\&mesSelecionado=0\&isPaginado=true.

Reis, L. E. (2017). Licitações e contratos: cases e orientações objetivas. Curitiba: Negócios Públicos.

Requi, E. M. dos S. (2015). Afinal, o que é credenciamento? Recuperado de https://www.zenite.blog.br/afinal-o-que-e-credenciamento/.

Ribeiro, J. A. (2011). Inexigibilidade de licitação e o credenciamento de serviços. . Recuperado de https://jus.com.br/artigos/18683/ inexigibilidade-de-licitacao-e-o-credenciamento-de-servicos/1.

TCU. (1995). Decisão n 656/1995. Plenário. Relator: Ministro Homero Santos. Sessão de 6 de dezembro de 1995. Diário Oficial da União, Brasília-DF, 28 dez.

TCU. (2010). Acórdão n 351/2010. Plenário. Relator: Ministro-Substituto Marcos Bemquerer Costa. Sessão de 3 de março de 2010. Diário Oficial da União, Brasília-DF, 5 mar.

TCU. (2013). Acórdão $n^{\circ}$ 1150/2013. Plenário. Relator: Ministro Aroldo Cedraz. Sessão de 15 de maio de 2013. Diário Oficial da União, BrasíliaDF, 21 mai.

TCU. (2017). Acórdão no 1545/2017. Plenário. Relator: Ministro Aroldo Cedraz. Sessão de 19 de julho de 2017. Diário Oficial da União, BrasíliaDF, 17 ago.

TCU. (2018a). Acórdão no 1191/2018. Plenário. Relator: Ministro Benjamin Zymler. Sessão de 23 de maio de 2018. Diário Oficial da União, BrasíliaDF, 11 jun.

TCU. (2018b). Acórdão n 784/2018. Plenário. Relator: Ministro Marcos Bemquerer. Sessão de 11 de abril de 2018. Diário Oficial da União, Brasília-DF, 23 abr.

Yin, R. K. (2003). Case Study Research: Design and Methods. (3. ed.). California: Sage. 